\title{
Positive Psychology in the Elementary Classroom: The Influence of Strengths-Based Approaches on Children's Self-Efficacy
}

\author{
Rod Galloway ${ }^{1,2}$, Bronwyn Reynolds ${ }^{1}$ \\ ${ }^{1}$ George Street Normal School, Dunedin, New Zealand \\ ${ }^{2}$ School of Education, University of Tasmania, Launceston, Australia \\ Email: rod@georgestreet.school.nz, Bronwyn.Reynolds@utas.edu.au
}

Received 8 August 2015; accepted 12 September 2015; published 18 September 2015

\begin{abstract}
Despite the positive psychology movement being relatively young and academic research is still building in this area, there is growing confidence that identifying and developing children's strengths could have profound long-term learning benefits. The intended outcome of this investigation is to contribute to the knowledge base about learning success when children's emerging preferences, passions and abilities are recognized and developed. This paper explores the foundations of strengths-based approaches for education and presents the findings of a case study that suggests strengths-based approaches have a positive effect on student self-efficacy.
\end{abstract}

\section{Keywords}

Strengths, Strengths-Based Approaches, Student Engagement, Well-Being

\section{Introduction}

Imagine for a moment that you are a school principal who has asked a group of parents to complete a satisfaction survey about their child's school. You might wonder what motivates parents to provide survey comments and even fear the worst, in the form of unpredictable, critical responses. Now imagine your interest in a recurring, positive theme that emerges in the survey results-for the seventh year in a row. When asked, what is working well for you and your child, parents with children attending one school in New Zealand have often responded with the same answer. In these real, not imaginary survey results, popular opinion amongst parents has repeatedly focused on strengths-based interventions. One parent commented, "Our son is thriving and learning at lots of levels. There has been a consistent responsiveness to his strengths as he has grown, without putting too much pressure on him. Thanks!”

Strengths-based philosophies are evident in New Zealand education policy statements, curriculum design and school descriptions. The pedagogy draws on ideas from positive psychology, differentiated instruction and the concept of student agency, but often lacks clarity around definitions and examples of evidence-based practice. Considering the growing acceptance of these philosophies and claimed improvements in children's learning and 
well-being, further research examining the influence of strengths-based approaches is warranted. Children's perceptions of how strengths influence their learning, with a particular focus on self-efficacy, follow as a qualitative case study.

\section{Project Background}

\subsection{Sample and Research Questions}

Eight boys and eight girls, aged 10 years old, were randomly selected to participate in the project, from an opportunity sample of 90 possible children of this age, attending a large urban, decile 9 (regarded as a high socioeconomic rating) school in New Zealand. These children had been involved in an existing strengths-based intervention, including a programme of identifying, applying and developing their strengths, for at least one year. Data gathering methods used in the current study were self-administered questionnaires involving 16 children; semi structured interviews involving 5 of these 16 children; and the analysis of documents produced by all child participants. The following questions were chosen to fulfill the aims of the research and provide a structure for the current study.

- Research question 1: How are children involved in strengths-based approaches?

- Research question 2: Do strength-based approaches influence children’s self-efficacy and if so, how?

\subsection{Ethical Considerations}

In pursuing responses to the research questions and the outcomes of this research, one of the researchers was aware of a dependency relationship (Mutch, 2013) [1] that existed by being an investigator and the principal of the school in which the research was conducted. Despite this unequal relationship, the research design included a strong element of student voice. Rather than being passive objects of this research, children were participating as social actors (Harcourt, Perry \& Waller, 2011) [2]. Issues of power, coercion and role conflict with children were identified by Mutch (2013) [1] and were addressed by disclosing the researcher's identity and role in the research to all participants and employing a research assistant, not associated with the school, to conduct all data gathering. The current research received ethics approval from the Human Resources Ethics Committee (Tasmania), on the basis of the research being conducted and that children's involvement was age appropriate, sensitive to their stage of development, open to modification, assented by each child and consented by parents.

\subsection{Literature Review}

Since 1998 there has been a "tectonic upheaval in psychology" (Seligman, 2011: p. 1) [3], which has formalized a long held, but less communicated belief that there is much to be gained by exploring what contributes to human happiness, accomplishment and well-being, rather than focusing primarily on human problems (Diener, 2011) [4]. The relatively recent and rapid rise in the activity and profile of positive psychology as the "science that investigates well-being” (Scorsolini-Comin, Fontaine, Koller \& Santos, 2013: p. 667) [5] has been thoroughly documented (Prezzler, 2011) [6]. Stebleton, Soria and Albecker (2012) [7] state that one direction to emerge from this new thinking is the application of positive psychology principles to education, sometimes referred to as strengths-based approaches. According to the Department of Education and Early Childhood Development, Australia (2012) [8], strengths-based approaches in education settings are "strategies that attempt to identify 'what works' for the child and 'how it works', so that those strategies can be continued and developed to match the child's abilities" (p. 5). A search of the available literature reveals five common underlying principles of positive psychology with children's strengths in mind:

- All children have strengths that can be valued and early recognition of these is beneficial (Department of Education and Early Childhood Development, 2012) [8];

- Children should be helped to identify their strengths (Green \& Norrish, 2013; Lippman, Moore \& McIntosh, 2011) [9] [10];

- Identifying what is successful for children without ignoring weakness, is important to their well-being (Huebner, Gilman, Reschly \& Hall, 2009; Kristjánsson, 2012) [11] [12];

- Strengths-based teaching and learning approaches can lead to greater well-being, which in turn allows children to flourish (Seligman, Ernst, Gillham, Reivich \& Linkins, 2009) [13].

Although Proctor, Maltby and Linley (2010) [14] found a positive correlation between strengths use and 
self-efficacy in a study involving tertiary students, no evidence was found in the literature to extend their claim to possible benefits for children. In light of these understandings, the results and discussion of findings for each research question is presented next.

\section{Results and Discussion}

\subsection{Research Question 1-Results}

The first research question related to how children are involved in strengths-based approaches at their school. As mentioned above, strengths-based approaches can be defined as "strategies that attempt to identify 'what works' for the child and 'how it works', so that those strategies can be continued and developed to match the child's abilities” (Department of Education and Early Childhood Development, 2012: p. 5) [8]. An analysis of data gathered from self-administered questionnaires, focus group interviews and documents reveal comprehensive participation of children in strengths-based approaches, described as the following findings:

- $\quad$ Children were aware of how strengths can be identified. Questions and suggestions in the documents provided were used by children to reflect on what some of their strengths could be. In addition, all of the 16 children who completed the self-administered questionnaire were able to define what they considered a strength to be, often referring to what they excelled at (16 children) and enjoyed doing (11 children) or described as an combination of excellence and enjoyment (nine children). Questionnaire responses to the question: "How did you discover you had this strength?” included references to opportunity, experimentation, encouragement and success. Comments included: "I decided to try out drama and discovered I really enjoyed it"; "I was complimented by the teacher and had my writing displayed"; and "I got picked for teams and won events". One interviewed focus group member remarked:

I didn't know that I was good at reading until we went to the bookshop and we saw lots of books and we went into a different section than we usually go into and I picked out Great Expectations and that really got me started reading big books.

- $\quad$ Strengths inventories for children were compiled. Lists of strengths, for example, were nominated and confirmed by children, parents and teachers. According to one of the focus group members, “...it's important that kids know that they have strengths".

- $\quad$ Children were encouraged to nominate a strengths-based goal. In two document types provided by children, nominated strengths were described as improvement goals. Children, teachers and parents reported on the progress and achievement of these goals by shading an appropriate "smiley face”. In another document, children were invited to describe the steps in achieving their strengths-based goal. Applying strengths in new and different ways was considered to be a strategy to learn about strengths by six children. Two other children provided written descriptions of their strengths-related goal progress.

- $\quad$ Children received support related to their strengths. Questionnaire responses by children, relating to identification and application of strengths, commonly referred to the significance of the encouragement of others. When answering the question "what helps you learn about your strengths?”, responses included: “Other people helping me"; "Someone else who also has the same strength as me can help me improve"; and "People telling you that you did something good".

- $\quad$ Children were provided with the opportunity to apply their strengths in a variety of curriculum areas. In mathematics, for example, children were invited to complete a "Student Progress and Achievement-Maths" graph, sharing areas of positive achievement and describe how they might build on that strength. Similarly, children's questionnaire responses revealed strength application in literacy (two children), sports (six children) and the arts (three children). Two interviewed children also referred to their strengths in sports and the desire to eliminate pre-activity preparation.

- $\quad$ Children described strengths application as enjoyable and important. All of the 16 children, who completed the questionnaire, claimed to appreciate the opportunity to use their strengths. Positive adjectives such as “awesome”, "happy”, “proud”, and “excited” were used to describe their feelings about applying their strengths. In addition, two children who were interviewed, spoke of the need to make use of strengths, e.g., “...if you had all these strengths and never used them there would be no point in having them" and "everybody needs to work on having their strength, and improving it and finding new ones".

- $\quad$ Children were provided with the opportunity to share their identified strengths with others. Sharing 
strengths was reported as being related to performance outcomes such as in art, sports, writing and drama. Documents were provided by three children that demonstrated strengths-related sharing in the form of drawing their strengths for public display and scholarship application letters.

\subsection{Research Question 1-Discussion}

Three themes of how children were involved in strengths-based approaches emerged from semi-structured interviews, questionnaires and documents provided by child participants. First, children had participated in a specific strengths identification process (Rawana, Latimer, Whitley \& Probizanski, 2009) [15] involving reflective activities. According to Madden, Green and Grant (2011) [16], a programme that assists children to identify their strengths must happen before children can apply and develop those strengths. Related strength identification strategies included being able to define a strength, recognising the strengths of others and compiling a personal strengths inventory. Brownlee, Rawana and MacArthur (2012) [17] suggest that strengths inventories are particularly useful for teachers building new relationships with children. Another aspect of the identification of strengths, which surfaced frequently in the findings, was the influence of other children. References to the encouragement, example and assistance of peers were made, often in relation to risk taking, improvement and, in the case of identification, the presence of a strength that children observe in others. The sharing of success in an area of strength may provide other children with ideas for their own to strengths. The influence of peers in the process of identifying children's strengths is suggested as a topic for further investigation.

The second consistent theme to emerge from the interview, questionnaire and document data sets, in understanding how children are involved in strengths-based approaches, was the implementation of strengths goal setting (Green \& Norrish, 2013) [9]. According to Morisano and Shore (2010) [18], children should be taught to set goals that are "specific, proximal, and reasonable, so that self-efficacy is bolstered and motivation grows" (p. 256). As an example, participants in the current study nominated a variety of goals related to their strengths. Two of the 16 children also provided an action plan, including drawings of intended results, outlining the steps required to achieve their strengths goal. Jones-Smith (2009) [19] reported that self-visualisation techniques are useful in creating a positive strengths focus. Another aspect of the strengths goal setting process, as reported in the findings was the role students have in monitoring their own progress and achievement. Swain (2005) [20] notes that if children are to understand their progress, they need to understand their goals and in association with their teachers, monitor progress. Forster and Souvigner (2014) [21], however, express caution in this area, after exploring the effects of child-set goals in relation to the reading progress of 900 fourth grade students. Findings suggest that although goal setting, with support from teachers, can improve motivation, unrealistic outcomesbased goals and student failure to attain those goals, can be demotivating and may contribute to negative selfimage and emotions (Cianci, Klein \& Seijts, 2010) [22], which conflicts with the ideals of strengths-based philosophies. Further research on effective strategies for setting mastery goals that focus on the effort and progress required developing strengths, rather than reaching strength-related performance targets, may assist in resolving this tension.

The last theme triangulated by all data sources, relating to how children are involved in strength-based approaches, was the significance of strengths application (Rawana, Latimer, Whitley \& Probizanski, 2009) [15]. Six of the 16 children, for example, stated in the questionnaire, that the best way to lean about their strengths was to use them. Norrish, Williams, O’Connor and Robinson (2013) [23] recommend that teachers allow children to develop strength-related skills and mindsets in different curriculum areas. An example of this suggestion was evident in the findings, with all 16 children describing strengths use in subjects such as mathematics, sport, art, literacy, drama and computing. According to Jones-Smith (2011) [19], strengths interventions should allow children to feel more comfortable and enthusiastic in the learning process and this was evident in the findings, particularly in descriptions of the perceived enjoyment and importance of strengths application.

In light of these themes, a topic for future investigation could be to examine the extent to which student well-being is linked to student achievement through the sequential order of strengths identification, goal setting and application in various curriculum contexts. A broader interpretation of strengths-based approaches, for example, could also include experiences that are receptive and responsive to children's existing competencies, with the purpose with the purpose of enhancing new learning and well-being. A potential aspect of establishing this suggested link, the relationship between children's strengths and their confidence, is considered next. 


\subsection{Research Question 2-Results}

The second research question framing the data analysis in the current study was designed to determine if children's strengths are related to their level of self-efficacy and if so, in what ways. Hattie (2012) [24] defines self-efficacy as "the confidence or strength of belief that we have in ourselves that we can make our learning happen" (p. 46). Words such as "confident" and "brave" were used in place of "self-efficacy" in the questionnaire and interview to increase understanding for children.

The proposition that self-knowledge of strengths builds confidence was affirmed by all children answering this section of the questionnaire (14 of the 16 children). The reasons provided by children to justify this positive response are grouped into two themes. First, 7 of the 16 children described a level of comfort in attempting new learning, due to memories of past success. One child, for example, was less nervous attempting different aquatic activities because of an existing swimming competence. Other similar comments included, "I found if I can do some things I might be able to do others"; "I have transferred my knowledge and skill to help me" and "I know I can do well”. This understanding of building upon success was also found in the documents provided by 15 of the 16 children participating in the study, relating to the process of strengths goal setting. Strengths-related selfefficacy transference was further explored in the focus group interview and included comments by four children:

...so if I'm good at maths and I know that I'm good at maths, I know that I can focus on something else;

...like, with sports I mean it will really help people um that um like their strength is maybe running um and the running connects to hockey because for hockey you need to be quick to get the ball;

... it would make you feel more confident in other things and feel like I could do this;

...I knew my strengths, I decided to give another one a go.

The second theme to emerge from the findings, connecting strengths with self-efficacy, is the notion that the development of confidence relies on a person's uniqueness, and willingness to practise, persevere and scaffold their strengths. One of the 16 children, for example, reported feeling more confident using a dance strength when shown and helped. Other supporting findings, related to uniqueness and practice, included comments from two children during the focus group interview: "I'm doing things a lot of people can't do"; and "usually I would be scared to go onto the stage and perform but because I knew what I was doing I wasn't".

The focus group interview revealed that while three children benefited from the encouragement of their parents to take risks outside areas of actual or potential strength, two of the five children interviewed expressed a preference to only participate in known activities they enjoyed or excelled in. Another child stated that developing confidence related to your strength did not necessarily mean developing confidence to share that strength with others. Across the findings, strengths-related self-efficacy was associated with sports, literacy, the arts and responding to questions.

\subsection{Research Question 2-Discussion}

The purpose of the second research question was to explore children's perceptions regarding any relationship between their strengths and level of self-efficacy. According to Hattie (2012) [24], children with high self-efficacy can be expected to embrace challenges, learn from their mistakes and make the effort to improve. The seminal work of Bandura (1993) [25], who defines self-efficacy as "people's judgements of their capabilities to organize and execute courses of action required to attain designated types of performance" (p. 391), provides a strong case for linking self-belief to successful outcomes. Furthermore, Prezzler (2011) [6] and Proctor, Maltby and Linley (2011) [14] suggest that the knowledge of strengths may affect student performance because efficacious beliefs can be associated with motivation and engagement. Despite these findings involving adults, a literature search reveals no documented studies that connect children's strengths with their level of self-efficacy. Sin and Lyubomirsky (2009) [26], caution against assuming that all positive psychology practices that are effective for adults will be effective for children. It is suggested, however, that if low self-efficacy is influenced by repeated failure (Hirvonen, Tolvanen, Aunol \& Nurmi, 2012) [27], it could be contended that high self-efficacy is influenced by repeated success. The findings in the current study do support the proposition that children's success in areas of strength is related to their levels of self-efficacy, as described by children in subjects such as literacy, sports, mathematics, and the arts. In addition, the current study suggests that involvement in age appropriate strengths identification processes assists self-awareness and talent recognition that may contribute to self-efficacy.

The significance of prior achievement is another aspect of self-efficacy worth noting (Hattie, 2012) [24]. 
Bowers (2009) [28] suggests that for children to capitalize on their strengths, teachers should provide encouragement and knowledge of success. The findings from the study reveal that children's knowledge of success can be separated into two categories. First, past success (e.g., memories of previous and successful tasks) was mentioned by three children in the current study to explain the strengths-related self-efficacy. A second category, in the form of the knowledge of current success, (e.g., practice, perseverance, partnering and scaffolding) was also considered to be a contributing factor to strengths-related self-efficacy by three children. Strengths may in this case, influence self-efficacy because of the child's current effort. In summary, the findings suggest that teachers, who use the memories of past success and knowledge of current success involving children's strengths, may increase self-efficacy. Furthermore, two of the five children, who were interviewed, expressed ideas relating to risk taking, because of their strengths. While increases in self-efficacy may be the result of past and current success, potential future success in the form of a willingness to attempt new experiences could be another outcome.

\subsection{Limitations}

In light of these findings, several limitations from this small-scale study are acknowledged. First, all research participants were children with potentially limited understanding of what was being asked of them (Mutch, 2013) [1]. While attempts were made to construct questions for interviews and self-administered questionnaires that were developmentally appropriate, it was accepted that there can be no assurances children fully understood each question. Secondly, children's ability to adequately communicate their opinions (Punch, 2009) [29] was acknowledged as a limitation, especially with respect to written responses. Finally, the 16 participants were recruited from one school that was classified as having a high socioeconomic rating. Increased opportunities to discover and develop strength-related interests, and therefore, potentially improved self-awareness, has been linked to higher family income (Lareau, 2011) [30].

\section{Conclusions}

The two research questions that frame this investigation were designed to explore children's perceptions of their involvement in strength-based approaches and to what extent this involvement influenced their level of self-efficacy. Findings from the data highlighted the following themes and potential implications for teachers:

- Children participated in a variety of strength-based approaches. These approaches can be viewed as a sequential order that link strength identification, application and development;

- Children set their own strength-related goals that targeted effort and progress;

- Children regarded the application of their strengths as desirable and important;

- Children regarded the example, encouragement and practical assistance of others as vital to the identification, application and development of their own strengths;

- Children's participation in an age appropriate strengths identification process encouraged self-awareness and talent recognition that may contribute to self-efficacy;

- Children believed that their strengths influenced their level of self-efficacy because of memories of past success and knowledge of current success. Potential future success in the form of risk taking could be a further result;

- A broader definition of strengths-based approaches for education, that encompasses identification and application of strengths in addition to aspects of well-being, may be required. The following example is offered: A strengths-based approach in education involves an intentional manner of teaching and learning that is receptive and responsive to children's existing competencies with the purpose of enhancing new learning and well-being.

Despite the limitations described, it is suggested that further research into strengths-based approaches could be shown to improve student self-efficacy and confirm the propositions listed above.

\section{References}

[1] Mutch, C. (2013) Doing Educational Research: A Practitioner’s Guide to Getting Started. 2nd Edition, New Zealand Council for Educational Research Press, Wellington.

[2] Harcourt, D., Perry, B. and Waller, T., Eds. (2011) Researching Young Children's Perspectives: Debating the Ethics and Dilemmas of Educational Research with Children. Taylor \& Francis, New York. 
[3] Seligman, M.E.P. (2011) Flourish: A Visionary New Understanding of Happiness and Well-Being. Free Press, New York.

[4] Diener, E. (2009) Positive Psychology: Past, Present, and Future. Oxford Handbook of Positive Psychology, 7-11.

[5] Scorsolini-Comin, F., Fontaine, A.M.G.V., Koller, S.H. and Santos, M.A.D. (2013) From Authentic Happiness to Well-Being: The Flourishing of Positive Psychology. Psicologia: Reflexão e Crítica, 26, 663-670. http://dx.doi.org/10.1590/s0102-79722013000400006

[6] Pressler, M.W. (2011) The Role of Strengths Focus to Improve Teaching and Learning. Unpublished Doctoral Dissertation, National-Louis University, United States of America.

[7] Stebleton, M. J., Soria, K. M. and Albecker, A. (2012) Integrating Strength-Based Education into a First-Year Experience Curriculum. Journal of College and Character, 13, 1-8.

[8] Department of Education and Early Childhood Development (2012) Strength-Based Approach. A Guide to Writing Transition Learning and Development Statements. State of Victoria, Australia.

[9] Green, L. S. and Norrish, J.M. (2013) Enhancing Well-Being in Adolescents: Positive Psychology and Coaching Psychology Interventions in Schools. In: Research, Applications, and Interventions for Children and Adolescents, Springer, Netherlands, 211-222. http://dx.doi.org/10.1007/978-94-007-6398-2_13

[10] Lippman, L.H., Moore, K.A. and McIntosh, H. (2011) Positive Indicators of Child Well-Being: A Conceptual Framework, Measures, and Methodological Issues. Applied Research in Quality of Life, 6, 425-449. http://dx.doi.org/10.1007/s11482-011-9138-6

[11] Huebner, E.S., Gilman, R., Reschly, A.L. and Hall, R. (2009) Positive Schools. Oxford Handbook of Positive Psychology, 561-569. http://dx.doi.org/10.1093/oxfordhb/9780195187243.013.0053

[12] Kristjánsson, K. (2012) Positive Psychology and Positive Education: Old Wine in New Bottles? Educational Psychologist, 47, 86-105. http://dx.doi.org/10.1080/00461520.2011.610678

[13] Seligman, M.E.P., Ernst, R.M., Gillham, J., Reivich, K. and Linkins, M. (2009) Positive Education: Positive Psychology and Classroom Interventions. Oxford Review of Education, 35, 293-311.

[14] Proctor, C., Maltby, J. and Linley, P.A. (2011) Strengths Use as a Predictor of Well-Being and Health-Related Quality of Life. Journal of Happiness Studies, 12, 153-169. http://dx.doi.org/10.1007/s10902-009-9181-2

[15] Rawana E., Latimer, K., Whitley, J. and Probizanski, M. (2009) Strength-Based Classroom Strategies for Teachers. Canadian Teacher Magazine. Pacific Edge Publishing, Canada. http://www.canadianteachermagazine.com/archives/ctm teaching ideas/nov09 strength-based classroom strategies.s $\underline{\mathrm{html}}$

[16] Madden, W., Green, S. and Grant, A.M. (2011) A Pilot Study Evaluating Strengths-Based Coaching for Primary School Students: Enhancing Engagement and Hope. International Coaching Psychology Review, 6, 71-83.

[17] Brownlee, K., Rawana, E.P. and MacArthur, J. (2012) Implementation of a Strengths-Based Approach to Teaching in an Elementary School. Journal of Teaching and Learning, 8.

[18] Morisano, D. and Shore, B.M. (2010) Underachievement and Goal Setting: Can Personal Goal Setting Tap the Potential of the Gifted Underachiever? Roper Review, 32, 249-258. http://dx.doi.org/10.1080/02783193.2010.508156

[19] Jones-Smith, E. (2011) Spotlighting the Strengths of Every Single Student: Why US Schools Need a New, StrengthsBased Approach. ABC-CLIO, Santa Barbara

[20] Swain, K.D. (2005) CBM with Goal Setting: Impacting Students’ Understanding of Reading Goals. Journal of Instructional Psychology, 32, 259-265.

[21] Förster, N. and Souvignier, E. (2014) Learning Progress Assessment and Goal Setting: Effects on Reading Achievement, Reading Motivation and Reading Self-Concept. Learning and Instruction, 32, 91-100. http://dx.doi.org/10.1016/j.learninstruc.2014.02.002

[22] Cianci, A.M., Klein, H.J. and Seijts, G.H. (2010) The Effect of Negative Feedback on Tension and Subsequent Performance: The Main and Interactive Effects of Goal Content and Conscientiousness. Journal of Applied Psychology, 95, 618. http://dx.doi.org/10.1037/a0019130

[23] Norrish, J.M., Williams, P., O’Connor, M. and Robinson, J. (2013) An Applied Framework for Positive Education. International Journal of Wellbeing, 3.

[24] Hattie, J. (2012) Visible Learning for Teachers: Maximising Impact on Learning. Routledge, New York.

[25] Bandura, A. (1993) Perceived Self-Efficacy in Cognitive Development and Functioning. Educational Psychologist, 28, 117-148. http://dx.doi.org/10.1207/s15326985ep2802_3

[26] Sin, N.L. and Lyubomirsky, S. (2009) Enhancing Well-Being and Alleviating Depressive Symptoms with Positive Psychology Interventions: A Practice-Friendly Meta-Analysis. Journal of clinical psychology, 65, 467-487. 
$\underline{\text { http://dx.doi.org/10.1002/jclp.20593 }}$

[27] Hirvonen, R., Tolvanen, A., Aunola, K. and Nurmi, J.E. (2012) The Developmental Dynamics of Task-Avoidant Behavior and Math Performance in Kindergarten and Elementary School. Learning and Individual Differences, 22, 715-723. http://dx.doi.org/10.1016/j.lindif.2012.05.014

[28] Bowers, K. (2009) Making the Most of Human Strengths. In: Lopez, S.J., Ed., Positive Psychology: Exploring the Best in People: Discovering Human Strengths, Praeger, Westport, 23-36.

[29] Punch, K.F. (2009) Introduction to Research Methods in Education. Sage, Thousand Oaks.

[30] Lareau, A. (2011) Unequal Childhoods: Class, Race, and Public Life with an Update a Decade Later. University of California Press, Los Angeles. 